\title{
LUZ, CÂMERA E AÇÃO: A IMPORTÂNCIA DA NARRATIVA NO PROCESSO DE ENSINO E APRENDIZAGEM NAS VIDEOAULAS
}

\author{
SÃO PAULO/SP MAIO/2018 \\ Jéssica Clementino da Costa - FCL - jcosta@casperlibero.edu.br \\ Janaíra Dantas da Silva França - FCL - jdsfranca@casperlibero.edu.br
}

Tipo: Relato de Experiência Inovadora (EI)

Categoria: Métodos e Tecnologias

Setor Educacional: EDUCAÇÃO SUPERIOR

\begin{abstract}
RESUMO
Este trabalho tem como objetivo apresentar um relato de experiência inovadora na construção de videoaulas do curso livre Direção em Audiovisual na Era Digital da Cásper Digital, Faculdade Cásper Líbero. As videoaulas do curso citado são inovadoras na medida em que apresentam três características que destoam do modelo padrão de videoaula que encontramos no meio acadêmico e corporativo: utilização de metalinguagem, construção de um arco narrativo com a inclusão do professor na cena dramática e produção audiovisual desenvolvida pelos próprios alunos. Acreditamos que estes três itens caracterizam uma experiência inovadora, pois a linguagem construída na produção audiovisual estudada apresenta estratégias didáticas eficientes que tornam o processo de aprendizagem mais atrativo, acessível, interativo e dialógico, elementos que colaboram para 0 desenvolvimento de um processo de ensino e aprendizagem de mais qualidade.
\end{abstract}

Palavras-chave: Cásper Digital; cursos livres; videoaula; inovação. 


\section{Introdução}

Nas últimas décadas, é possível acompanhar a efervescência do surgimento de novas tecnologias. Isso ocorre, sobremaneira, devido ao fenômeno da globalização, que se acentua a partir da união dos mercados financeiros de diferentes países, além de fomentar a quebra de fronteiras políticas e culturais.

A educação acompanha esse fenômeno e vemos emergirem, cada vez mais intensamente, cursos mediados pela tecnologia, em um contexto no qual professor e aluno não precisam mais estar juntos em um mesmo espaço geográfico para fazer acontecer o processo de ensino e aprendizagem.

A esse "modo" de fazer educação damos o nome de Educação a Distância (EAD), que, segundo Filatro (2010), é "a modalidade de educação em que a maior parte da comunicação entre professor e aluno é mediada por recursos tecnológicos" (FILATRO, 2010, p. 31).

De acordo com a mesma autora, a presença das tecnologias no ambiente escolar e acadêmico está cada vez mais intensa no mundo, como é possível ver pela tabela a seguir, que mostra a penetração das tecnologias no universo escolar em países como Canadá, Estados Unidos e Inglaterra.

Tabela 1 - Porcentagem de escolas com acesso à internet (no mundo).

\begin{tabular}{|c|c|c|}
\hline \multirow{2}{*}{ País } & \multicolumn{2}{|c|}{ Escolas conectadas } \\
\cline { 2 - 3 } & Ensino Fundamental & Ensino médio \\
\hline Canadá & $88 \%$ & $97 \%$ \\
\hline Estados Unidos & $88 \%$ & $94 \%$ \\
\hline Inglaterra & $17 \%$ & $83 \%$ \\
\hline
\end{tabular}

Fonte: Veja Digital, Edição Especial, São Paulo, dezembro de 1999 citado por FILATRO, 2010, p. 27.

No Brasil, apesar de menos expressivo, também é possível observar o mesmo movimento crescente da utilização de tecnologias nos meios escolares e acadêmicos. Segundo o Mapa da exclusão digital de 2013, houve um crescimento significativo de acesso à internet nas escolas brasileiras de 1997 para 2001. Neste ano, a porcentagem de escolas conectadas do Ensino Fundamental e Médio foi, respectivamente, 10\% e $44 \%$.

Além disso, o Censo EAD.BR 2016 mostrou que houve um crescimento da oferta de cursos na educação básica e na pós-graduação stricto sensu entre os anos de 2015 e 
2016. Veja o gráfico a seguir:

Gráfico 1 - Crescimento da oferta de ursos na educação básica e na pós-graduação stricto sensu.

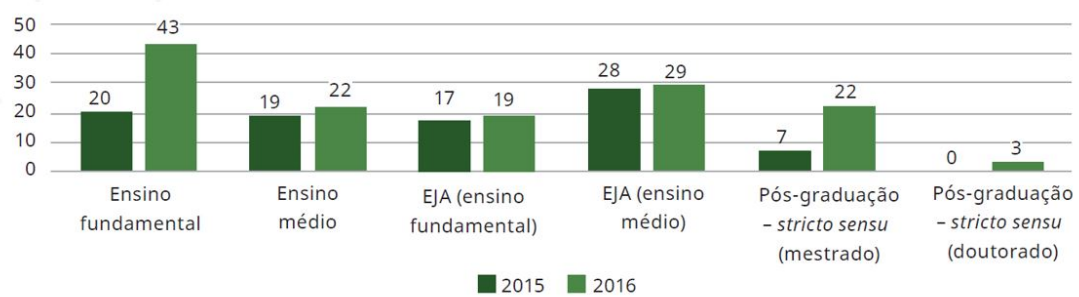

Fonte: EAD.BR 2016, p. 74.

Esses dados nos mostram que no Brasil, a EAD conquista cada vez mais adeptos, justamente por possibilitar o acesso à educação de uma maneira mais inclusiva, uma vez que mais vagas são abertas e mais oportunidades de estudos são construídas, principalmente para aqueles que não possuem condições de estar em um espaço externo específico para estudar.

Um dos formatos de apresentação de conteúdo mais utilizados na EAD é a videoaula. Isto ocorre, pois este recurso apresenta elementos pedagógicos familiares ao aluno, isto é, a figura do professor expondo um conteúdo para um aluno (elemento também presente na educação presencial).

Sobre este aspecto, Camargo, Garofalo e Coura-Sobrinho (2011) afirmam que

\begin{abstract}
A videoaula é um gênero que claramente absorve características da aula presencial, como a existência de um enunciado expositivo, planejado e muitas vezes apresentado por um professor, com a intenção de levar conhecimento ao aluno em um processo de ensino-aprendizagem. Entretanto, ele traz novas características, como a utilização da mídia audiovisual, a interação assíncrona ou ausência de interação com os alunos, a possível utilização simultânea de várias linguagens visuais que podem ser combinadas com o áudio, etc. (CAMARGO, GAROFALO, COURA-SOBRINHO, 2011, p. 83).
\end{abstract}

Nesse cenário, os professores precisam passar por um processo de adaptação e migração de estratégias pedagógicas e de linguagem utilizadas na educação presencial para a educação a distância. Para Gerbase (2006), a dificuldade de adaptação dos professores na utilização de tecnologias da informação e comunicação como a videoaula, ocorre, pois, migrar da sala de aula presencial para a sala de aula audiovisual requer uma mudança profunda de linguagem por parte do professor, que, de protagonista passa a ser colaborador neste novo formato.

Para que uma videoaula consiga atingir seu principal objetivo, ou seja, ensinar e 
transmitir conhecimento aos alunos de modo eficaz e prazeroso, é vital que saibamos dominar e compreender a linguagem interativa e dialógica. Segundo Freire (1995), o educar e o aprender devem passar, necessariamente, pelo diálogo. Desse modo, diz o autor: "a experiência dialógica é fundamental para a construção da curiosidade epistemológica. São constitutivos desta: a postura crítica que o diálogo implica; a sua preocupação em apreender a razão de ser do objeto que medeia os sujeitos dialógicos" (FREIRE, 1995 p.81 citado por PIVA JR.; FREITAS; MISKULIN, 2009, p.03).

Tendo essa premissa em mente, é importante que, ao construir uma videoaula, o professor e a equipe que o auxilia a construir as aulas e os recursos midiáticos invistam em uma proposta interativa e dialógica, sendo esta um elemento facilitador para a aprendizagem. Segundo Sena (2012), não considerar estes elementos reduz as videoaulas a recursos massificados e homogeneizados, levando o aluno a uma posição de espectador do processo de ensino e aprendizagem.

Pensando nestes aspectos, e objetivando construir videoaulas mais interativas e dialógicas, a Cásper Digital pensou em um novo formato de videoaulas para seus cursos livres. No formato proposto, avaliou-se como transmitir a mensagem das videoaulas por meio de um canal de transmissão eficaz e interativo. Nas próximas seções, vamos apresentar este formato, a estrutura da Cásper Digital e dos cursos livres oferecidos.

\section{A Cásper Digital}

Núcleo de educação a distância da Faculdade Cásper Líbero, a Cásper Digital existe desde 2016 e dedica-se a estudar as necessidades de formação e aperfeiçoamento dos profissionais de comunicação demandadas pelas organizações públicas e privadas em cenários de alta competividade, planejando e ofertando cursos de curta duração (cursos livres) e de pós-graduação nas modalidades a distância (totalmente on-line).

A Cásper Digital oferece cursos que são estruturados de forma que a tradição e a excelência no ensino da comunicação sejam mantidas e ampliadas pela inovação tecnológica.

Sua missão é promover a formação ética, humanística e profissional de seus alunos, avançando nas fronteiras do conhecimento e do saber em comunicação por meio das novas tecnologias, estimulando a reflexão, a criação, a produção, a inovação e a aplicação, de forma a contribuir efetivamente com o desenvolvimento e com o aperfeiçoamento de profissionais para atuarem como protagonistas nas diversas esferas sociais do país. 


\section{Cursos livres}

Em fevereiro de 2018, a Cásper Digital lançou dois cursos livres: Direção em Audiovisual na Era Digital, cuja autoria é do professor, diretor e cinema Ninho Moraes, e Jornalismo Digital, de autoria da professora jornalista Ana Brambilla.

O curso de Direção em Audiovisual na Era Digital é voltado para o estudante que deseja aprender técnicas para a produção audiovisual em plataformas digitais. Já o curso Jornalismo Digital é voltado para os profissionais que desejam se apropriar de técnicas de desenvolvimento de escrita para a elaboração de conteúdo digital em diferentes formatos como texto, vídeo e áudio.

Os dois cursos livres possuem a seguinte estrutura:

- Público-alvo: graduados, estudantes de graduação e demais interessados;

- Três videoaulas: abertura, aula 1 e 2;

- Carga horária: 32 horas-aula;

- Níveis: iniciante e intermediário;

- E-book interativo e para impressão;

- Materiais complementares;

- Quizzes.

Os dois cursos são autoinstrucionais, ou seja, não precisam de tutoria para o aluno aprender o conteúdo.

Neste artigo, vamos analisar a estrutura das videoaulas do curso Direção em Audiovisual na Era Digital.

\section{Videoaulas}

Cada videoaula do curso de Direção em Audiovisual na Era Digital possui, no máximo, 5 minutos de duração. Sendo a videoaula de apresentação a de menor duração, em tono de 30 segundos.

Desde o início da construção das videoaulas deste curso, a proposta não foi reproduzir o ambiente da educação presencial, mas sim criar uma linguagem própria para EAD e a identidade da Cásper Digital, mantendo as características da excelência, tradição e inovação da Faculdade Cásper Líbero. 
A seguir, apresentamos três características inovadoras das videoaulas produzidas para o referido curso. Analisaremos, especificamente, a videoaula 1 "Não erre no básico", de 4 minutos e 28 segundos.

\subsection{Metalinguagem}

O objetivo da videoaula "Não erre no básico" é mostrar os erros mais comuns que são cometidos nas produções audiovisuais. Ao longo do vídeo, o professor apresenta sete erros básicos, que são: câmera fora do foco, ator ou apresentador fora do ponto de luz, gravação em ambiente com barulho, gravação em fundo chapado, problemas com figurino, gravação na contraluz e escolha de paleta de cores.

A explicação de cada erro não ocorre apenas por meio da fala do professor, mas também a partir da elaboração de uma cena ficcional que é construída a partir do erro especificado pelo professor na videoaula. Assim o arco narrativo criado é o meio pelo qual o conteúdo da aula (erros de uma produção audiovisual) é explanado: a cena ficcional é o tema e o meio da instrução dada pelo professor, que, por sua vez, também compõem toda a misancene. Esse tipo de estrutura é o que define uma metalinguagem, isto é, utiliza-se de uma linguagem (no caso, a cena ficcional com erros básicos de produção audiovisual) para falar sobre a própria linguagem (a produção audiovisual).

Além disso, logo no início da videoaula, o autor explica como foi o processo de construção do próprio vídeo que estamos assistindo a fim de explicar os passos da construção de uma produção audiovisual.

Imagem 1: construção do roteiro do vídeo.

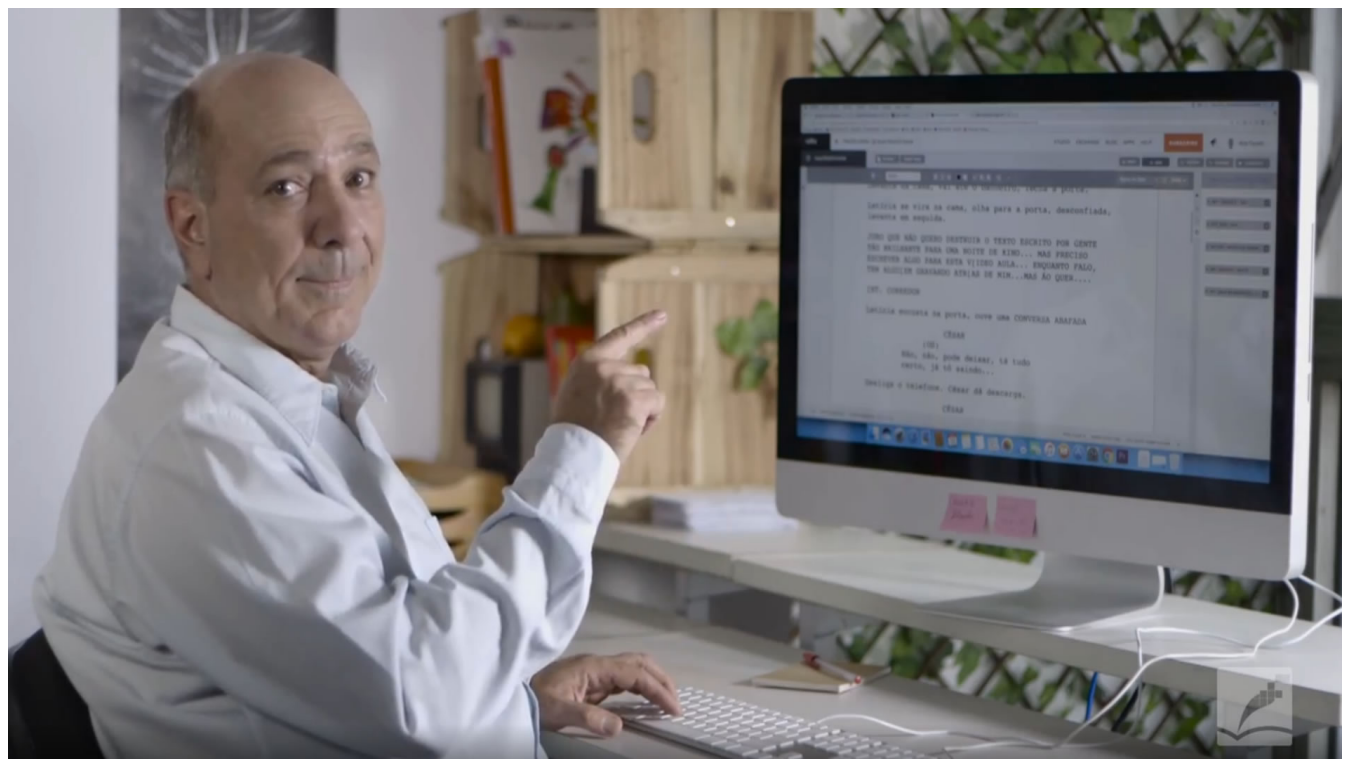


Compor uma videoaula a partir de uma perspectiva metalinguística é inovador do ponto de vista didático, pois o aluno consegue visualizar a prática do que está sendo explicado na teoria, constituindo uma aprendizagem mais ativa do que puramente contemplativa.

\subsection{Arco narrativo com a inclusão do professor na cena dramática}

Uma construção ficcional é comum em produções audiovisuais de cinema e TV. Utilizála em uma videoaula é inovador pois este meio é caracterizado, normalmente, por um cenário chapado, no qual o professor autor faz uma exposição linear do conteúdo da aula amparado por suportes como editores de apresentação (como o PowerPoint) ou Screencast (captação da tela do computador em atividade).

Além do roteiro de conteúdo da aula, a videoaula em análise é caracterizada pelo seguinte arco narrativo: um casal entra em cena brigando (o motivo da briga não nos é revelado) e a cena culmina com o assassinato do marido pela esposa. Nas cenas seguintes, vemos o funeral do marido assassinado no qual aparecem além da viúva, outros coadjuvantes.

Imagem 2: briga entre o casal.

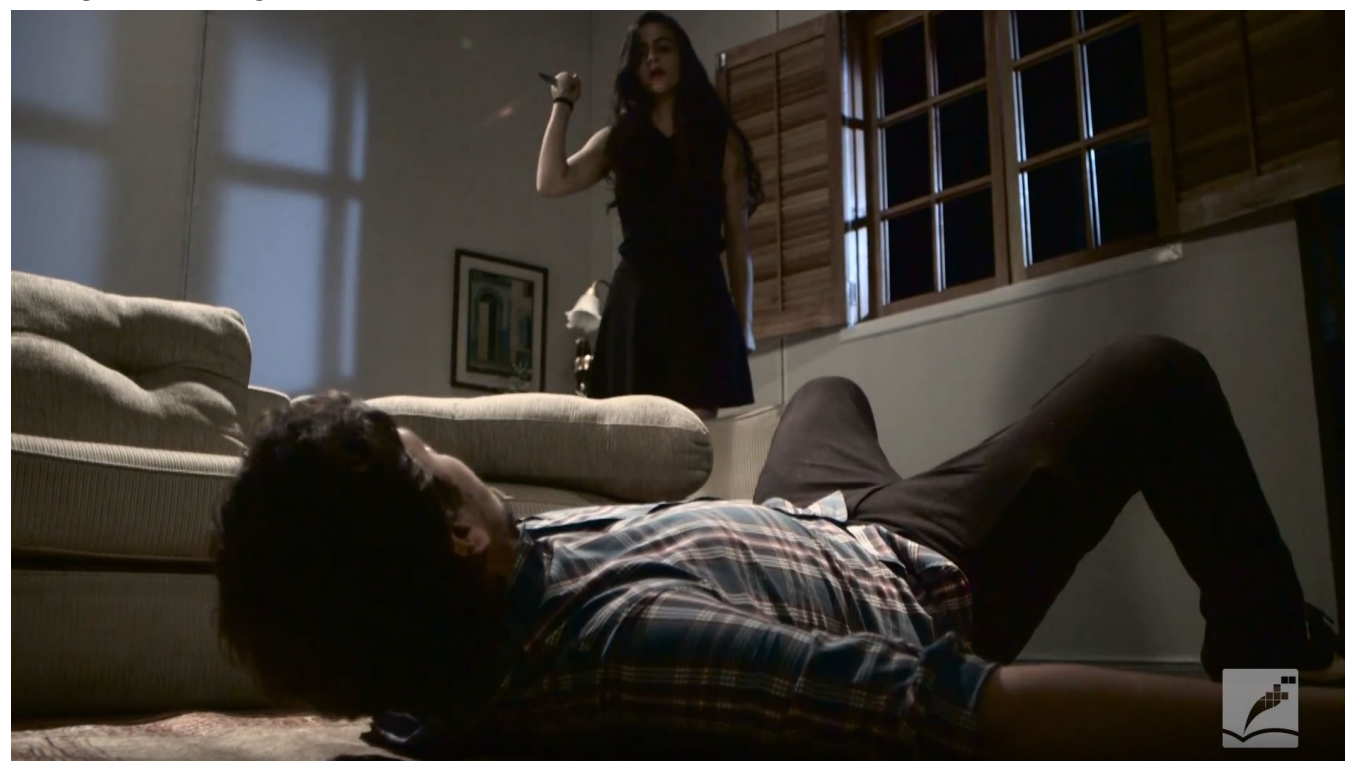

Além disso, o professor também é incluído em toda a cena dramática, o que além de criar uma linguagem mais dialógica, constrói uma atmosfera mais leve e divertida, facilitando o processo de aprendizagem.

Inclusive, este é um elemento que diferencia a videoaula do curso Direção em Audiovisual na Era Digital de outros formatos de cursos que apresentam videoaulas com 
dramatização, como é o caso do Telecurso da Fundação Roberto Marinho. Nesse caso, a teleaula apresenta uma cena ficcional, mas esta é apresentada à parte da fala e explicação do narrador (que assumiria o papel do professor) que não é incluído na cena.

Imagem 3: inclusão do professor nas cenas ficcionais.

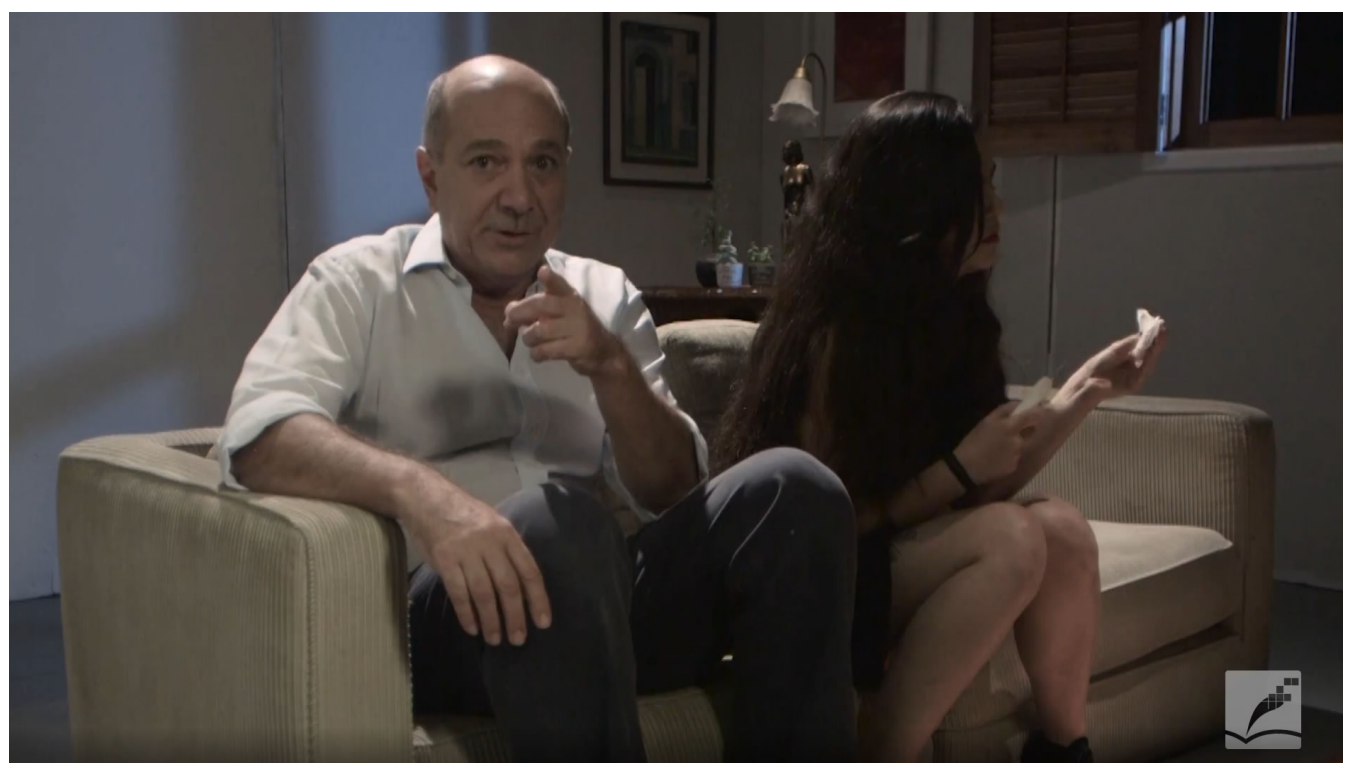

\subsection{Produção audiovisual desenvolvida pelos próprios alunos}

As videoaulas dos cursos livres da Cásper Digital foram desenvolvidas em parceria com a Produtora Experimental e Audiovisual da Faculdade Cásper Líbero. Na produtora, os próprios alunos da faculdade realizam produções audiovisuais ficcionais e não-ficcionais para a web.

Formado por colaboradores júnior, pleno e por um monitor, a Produtora Experimental é um espaço de aprendizado para os alunos do curso de audiovisual e também uma forma de divulgar os trabalhos dos alunos da Faculdade Cásper Líbero, fomentando a cultura e o estilo casperiano na mídia.

Este tipo de proposta configura uma visão horizontal de desenvolvimento multimídia, uma vez que toda a produção e mensagem midiática a ser entregue ao aluno do curso livre é produzida também por alunos, criando uma linguagem mais acessível e um olhar mais específico, voltado para o aluno.

\section{Considerações finais}


Neste artigo, analisamos a estrutura da videoaula "Não erre no básico" do curso Direção Em Audiovisual para a Era Digital, de autoria do professor Ninho Moraes e produzida e roteirizada pela Cásper Digital.

Vimos que a proposta desta videoaula é inovadora, pois apresenta três características que destoam do modelo padrão de videoaula: utilização de metalinguagem, construção de um arco narrativo com a inclusão do professor na cena dramática e produção audiovisual desenvolvida pelos próprios alunos.

A videoaula construída com estes elementos mostrou-se mais interativa e dialógica, uma vez que o aluno matriculado pode se sentir parte do processo de ensino-aprendizagem construído pelo autor-professor. Este aspecto pode ser comprovado por meio do resultado de uma pesquisa de satisfação realizada com alunos matriculados nos cursos livres. Neste questionário, a maior parte dos alunos sugeriu, para os próximos cursos, a criação de mais videoaulas, o que demonstra a adesão deste formato pelos alunos.

Esse retorno positivo nos evidencia que a proposta de videoaula implementada pela Cásper Digital conseguiu contribuir para uma educação de mais qualidade, uma vez que o conteúdo do curso foi transmitido a partir de um veículo interativo, eficaz e inovador.

\section{Referências}

ABED - ASSOCIAÇÃO BRASILEIRA DE EDUCAÇÃO A DISTÂNCIA. Censo ead.br: relatório analítico da aprendizagem a distância no Brasil. Curitiba: InterSaberes, 2017. Disponível em: < http://abed.org.br/censoead2016/Censo_EAD_2016_portugues.pdf>. Acesso em: 07 maio 2018.

CAMARGO, Leonardo D. V. L.; GAROFALO, Simone; COURA-SOBRINHO, Jerônimo. Migrações da aula presencial para a videoaula: uma análise da alteração de médium. Quaestio. Sorocaba, SP, v. 13, n. 2, p. 79-91, nov. 2011. Disponível em: http://docplayer .com.br/9876868-Migracoes-da-aula-presencial-para-a-videoaula-uma-analise-daalteracao-de-midium-1.html. Acesso em: 23 abr. 2018.

DOTTA, Silvia C.; JORGE, Erica F.C.; PIMENTEL, Edson P.; BRAGA, Juliana C. Análise das Preferências dos Estudantes no uso de Videoaulas: Uma experiência na Educação a Distância. II Congresso Brasileiro de Informática na Educação (CBIE 2013) XIX Workshop de Informática na Escola (WIE 2013). DOI: 10.5753/CB 21 IE.WIE, 2013.

FILATRO, Andrea. Design Instrucional Contextualizado: educação e tecnologia. 3. ed. 
São Paulo: Editora Senac São Paulo, 2010.

FREIRE. Paulo. À sombra desta mangueira. São Paulo: Livraria Nova Sede, 1995.

GERBASE, Carlos. Desafios na construção de uma estética audiovisual para a educação a distância. Logos 24: Cinema, imagens e imaginário. Ano 13, 1ำ semestre 2006. Disponível em: . Acesso em: 23 abr. 2018.

PIVA JR. Dilermando; FREITAS, Ricardo Luiz de; MISKULIN, Rosana, G. S. Linguagem Dialógica Instrucional: A (re)construção da linguagem para cursos online. In.: Congresso Internacional ABED de Educação a Distância (CIAED), 15․ 2009. Fortaleza/CE. Anais. Disponível em: http://www.abed.org.br/congresso2009/CD/trabalhos/752009101016.pdf. Acesso em: 23 abr. 2016.

SENA, Eni de Faria. As videoaulas de um curso a distância: obstáculos didáticos/pedagógicos e suas implicações na aprendizagem do aluno. SIED - Simpósio Internacional de Educação a Distância. EnPED - Encontro de pesquisadores em Educação a distância. Universidade Federal de São Carlos, São Carlos, 10 a 22 set., 2012. 